\title{
LIMITAÇÕES DE AUTONOMIA POLÍTICO-ADMINISTRATIVA DE MUNICÍPIOS E OS FATORES DE DESENVOLVIMENTO TERRITORIAL
}

\author{
LIMITATIONS OF POLITICAL-ADMINISTRATIVE AUTONOMY IN \\ MUNICIPALITIES AND FACTORS OF TERRITORIAL DEVELOPMENT
}

\author{
Juliane Manfrin Bernardy ${ }^{1}$ \\ Rógis Juarez Bernardy ${ }^{2}$ \\ Augusto Fischer ${ }^{3}$
}

\begin{abstract}
Resumo
A ausência de capacidade de mantenimento da maioria dos municípios brasileiros não difere da realidade encontrada nos municípios em Santa Catarina, especialmente na região Oeste. Neste contexto, esta pesquisa tem por objetivo analisar os aspectos vinculados à autonomia dos entes municipais, com base em indicadores socioeconômicos, demográficos e de receitas públicas municipais de duas microrregiões do IBGE: Chapecó e São Miguel do Oeste. O estudo possui abordagem predominantemente quantitativa, complementada por aporte qualitativo. Caracteriza-se como estudo multicaso, visto que está centrado nas duas microrregióes, constituídas por 59 municípios. Por sua dinâmica econômica, as microrregiões apresentam deficiências estruturais para a ampliação das atividades industriais e de serviços, consideradas mais "nobres", em termos de qualificação de trabalho e renda. As técnicas e os instrumentos de pesquisa foram norteados em base de dados secundários e também primários, por meio de entrevistas aos gestores públicos municipais. Como técnicas de análise dos dados foram geradas tabelas de análise das variáveis independentes, dependentes e intervenientes/moderadoras, vinculadas à infraestrutura de vias regionais, com diferentes tipologias. Como principais resultados observou-se que o posicionamento geográfico com acesso secundário e/ou conexão indireta possui predomínio da atividade econômica agropecuária, de baixo rendimento de impostos e, apresenta acentuada variação populacional negativa. De forma diferenciada as cidades medianas localizadas no eixo viário principal possuem determinadas dinâmicas econômicas centradas no segmento industrial e de serviços urbanos que os tornam interessante do ponto de vista do desenvolvimento e equilíbrio regional.
\end{abstract}

Palavras-chave: Pequenos Municípios. Receitas Públicas. Assimetrias Regionais. Variação Populacional. Corredores de Desenvolvimento.

\footnotetext{
${ }^{1}$ Mestre em Administração pela Unoesc Chapeco (UNOESC). Professora pelo Sebratep Educacional, Pólo de Joaçaba - SC, Brasil. E-mail: julianemanfrin@hotmail.com

${ }^{2}$ Doutor em Engenharia Civil pela Universidade Federal de Santa Catarina (UFSC). Professor da Universidade do Oeste de Santa Catarina (UNOESC), Chapecó - SC, Brasil. E-mail: rogis.bernardy@unoesc.edu.br

${ }^{3}$ Doutor em Administração pela Universidade de São Paulo (USP). Professor da Universidade do Oeste de Santa Catarina (UNOESC), Chapecó - SC, Brasil. E-mail: augusto.fischer@unoesc.edu.br
} 


\begin{abstract}
The lack of maintenance capacity of most Brazilian municipalities does not differ from the reality found in the municipalities in Santa Catarina, especially in the West. In this context, this research has the aim of analyzing the aspects linked to the autonomy of the municipal entities, based on socioeconomical, demographical and municipal public revenue indicators of two microregions of IBGE: Chapecó and São Miguel do Oeste. The study has a quantitative approach, supplemented by qualitative contribution. It is characterized as multiple case, since it is focused on the two microregions, constituted by 59 municipalities. Due to this economic dynamic, the microregions present structural deficiencies for the expansion of the industrial and service activities, considered more "noble", in terms of work and income qualification. The research techniques and instruments were guided by research in a database, predominantly in secondary data, and also primary, through interviews with the municipal public managers. As techniques of data analysis, tables of the independent, dependent, and participant/moderating variables were created, linked to the infrastructure of regional routes, with different typologies. As main results it was observed that the geographic position with secondary access and/or indirect connection has predominance of the agricultural economic activity, with low income of taxes, and presents significant negative populational variation. Differently, the medium-sized cities located at the main thoroughfares have certain economic dynamics focused on the industrial and urban service segment that make them interesting from the point of view of the regional development.
\end{abstract}

Keywords: Small municipalities. Public revenues. Regional asymmetries. Populational variation. Developmental corridors.

\title{
Introdução
}

Ao se discutir a presença ou ausência de desenvolvimento de um território ou região, se faz a conexão direta ao papel que deve ser desempenhado pelos municípios como fonte principal na promoção das condições de desenvolvimento. No entanto, devido ao alto custo da estrutura pública, principalmente com pessoal e carência de planejamento orçamentário, ficam às margens da dependência das transferências intergovernamentais, embora, parte desta renda também seja gerada no próprio local.

Estudo da Firjan, sobre a gestão fiscal municipal demonstrou que $82 \%$ dos municípios não geraram nem $20 \%$ de suas receitas, e sob essa condição ficam dependentes de verbas que vêm de fontes externas à sua arrecadação (Federação das Indústrias do Rio de Janeiro - FIRJAN, 2016). Neste aspecto, se evidência a problemática da pesquisa que com a ausência de capacidade de gerar suas próprias receitas públicas, os municípios ficam dependentes das transferências intergovernamentais o que limita sua capacidade de desenvolvimento.

Vinculadas a uma série de indicadores, as características da realidade local demandam pesquisas. Por isso, este estudo tem por objetivo analisar os aspectos vinculados à autonomia dos entes municipais, com base em indicadores socioeconômicos, demográficos e de receitas públicas municipais de duas microrregiões: Chapecó e São Miguel do Oeste, bem como os demais vetores de desenvolvimento presentes, ou não, na região, como a infraestrutura viária, considerada uma dimensão essencial de desenvolvimento básico.

Com base na importância e responsabilidade que o município possui quanto ao desenvolvimento de seu território e região, que esta pesquisa, de maneira específica se propôs: (a) tipificar os municípios quanto à sua acessibilidade viária aos corredores de desenvolvimento regional; (b) examinar a representatividade das receitas próprias e de transferências intergovernamentais; (c) analisar os dados socioeconômicos municipais, relacionando-os com a acessibilidade viária regional; (d) relacionar os dados socioeconômicos com as receitas públicas municipais. Quanto ao processo metodológico se caracteriza como um estudo multicaso, por contemplar duas microrregiões, que juntas contemplam 59 municípios. Caracteriza-se predominantemente pela abordagem quantitativa, com complementação da abordagem qualitativa que serviu como subsídio para explorar características e comportamentos assimétricos do ambiente da pesquisa. 
Quanto à estrutura, este artigo está organizado em seções, que além desta introdução, apresenta uma revisão teórica que serve de suporte à pesquisa. Também se apresenta os procedimentos metodológicos, seguido da análise e discussão dos resultados e, por fim, as considerações finais.

\section{Carência de autonomia político-administrativa de municípios}

Ao versar sobre o desenvolvimento e economia regional, é comum atribuir a responsabilidade ao estado e municípios, em função da autonomia lhes auferida por meio da Constituição Federal de 1988. Não somente questões políticas fizeram aumentar a responsabilidade dos municípios. O crescimento econômico e populacional exerceu forte contribuição para esta condição, uma vez que adicionou a este contexto outras problemáticas decorrentes do crescimento, sobretudo em pequenos e médios municípios (FIGUEIREDO; LEITE, 2006). Para os autores, promover condições de desenvolvimento e criar diferenciais competitivos, não é um fenômeno macroeconômico, influenciado por variáveis exógenas à realidade regional, mas sim, fruto de um processo interno de diferenciação nas práticas gerencias e exploração das potencialidades.

$O$ processo de descentralização fiscal no sistema federativo, formalizado e consagrado na reforma constitucional em 1988, deu-se por meio da Constituição Federal (PRADO, 2001) beneficiou os governos locais com a ampliação das transferências federais e estaduais a esses entes que assumiram a administração própria de assuntos de gestão pública, especialmente, em relação aos tributos de sua competência e à organização dos serviços públicos (BATISTA, 2015), além de assumir o compromisso de promotor do desenvolvimento econômico.

No entanto, a dependência das transferências intergovernamentais, o alto gasto da estrutura pública, principalmente com pessoal, a carência de planejamento orçamentário, insere os municípios em um cenário nada promissor. Dos 5.570 municípios, mais de 3.000 têm sua receita oriunda das transferências constitucionais, como o Fundo de Participação dos Municípios - FPM (BOVO, 2001). Mendes (2004, p. 447) mostra que, em 2002, 58\% dos municípios tiveram nas transferências recebidas pelo menos $90 \%$ de suas receitas correntes.

A estrutura das receitas públicas municipais, que compõem o orçamento municipal emana de uma integração sistêmica, que abrange desde as atividades econômicas, densidade populacional, demanda por serviços públicos, até os repasses intergovernamentais, como o FPM. Para muitos municípios, o FPM é a maior fonte de receita, responsável pelo mantenimento da estrutura pública. Além disso, boas relações institucionais com Estados e União, também podem gerar receitas provenientes de convênios com os ministérios ou mesmo pelas chamadas transferências voluntárias - emendas parlamentares (ARRAIS, 2014).

O FPM tem como objetivo redistribuir rendas entre os entes federados (Fecam, 2019) e os valores que o compõem são provenientes de dois impostos da União: o imposto sobre a renda - IR (Art. 153, III da Constituição); e o imposto sobre produtos industrializados - IPI (Art. 153, IV). Para a sua distribuição se utiliza como base a composição populacional dos estados e municípios e os critérios dividem os municípios em três categorias: as chamadas faixas populacionais, com coeficiente individual, conforme previsto na Lei $\mathrm{n}^{0}$. 5.172/1966 - Código Tributário Nacional e Decreto-Lei $\mathrm{n}^{\circ}$. 1.881/1981 (CNM, 2012; MONASTERIO, 2013).

Monasterio (2013) argumenta que tais critérios foram responsáveis pelo intenso movimento de criação de municípios após a Constituição Federal de 1988, pois pelo coeficiente mínimo (0,6 até 10.188 habitantes), se este fosse dividido em dois, faria com que os dois novos municípios dobrassem suas participações no FPM. No período de 1991 a 2000, 1.016 municípios foram criados, sendo que destes, apenas 40 possuíam mais de 20 mil habitantes.

Em Santa Catarina, dos 295 municípios, 76 foram criados entre 1991 e 2000, e outros dois em 2012 (DA SILVA; DE OLIVEIRA ROCHA, 2012). No decorrer da década de 1990, alterações legais reduziram os incentivos e as facilidades para a emancipação (MONASTERIO, 2013). A Emenda Constitucional $\mathrm{n}^{\circ} 15$ de 1996 apresentou requisitos mais rígidos e específicos a serem obedecidos nos procedimentos acerca da criação de entes administrativos.

Em relação ao ISSQN e IPTU, que são de competência municipal, Abrucio e Couto (1996) destacam que estes apresentam maior potencial de arrecadação nos médios e grandes municípios, visto que a base econômica dos pequenos é eminentemente agropecuária. Neles o rendimento de empreendimentos implementados na propriedade urbana é pouco significativo e o setor de serviços pouco expressivo. A quota parte de ICMS pertencente aos municípios (25\% do total arrecadado pelo estado) possui critérios de transferência, como a influência da intensidade de produção econômica, 
ou seja, "os valores transferidos estão relacionados com capacidade de geração de riqueza no âmbito municipal. [...] a lógica preponderante deste imposto é a de premiar os municípios economicamente mais bem-sucedidos" (ABRUCIO; COUTO, 1996, p. 44).

Neste interim, a debilidade de receitas municipais próprias também é um indicativo da fragilidade das bases econômicas de um ente administrativo, de forma que existe uma relação direta entre tipologias de atividades econômicas a capacidade de geração de receitas, advindas dos tributos. A este tema se acrescenta as dificuldades dos pequenos municípios terem estrutura de atividades econômicas consideradas "nobres", normalmente centradas no segmento de serviços e localizadas em ambiente urbano (REIS; 2015).

\section{Fatores de desenvolvimento territorial}

Assumir que têm desigualdade entre as regiões, é reconhecer que não existe uniformidade no desenvolvimento. Algumas apresentam desempenho econômico melhor que outras, enquanto determinadas regiões prosperam, outras sofrem com baixo ou mesmo índices negativos de desenvolvimento, o que forma as assimetrias regionais (MORAES, 2014; REIS, 2015). Estas desigualdades regionais acabam por distanciar ainda mais o desenvolvimento de municípios, como os pequenos, ao gerar um fluxo de saída populacional para outros centros mais desenvolvidos, em busca de melhores oportunidades de trabalho e renda.

O desenvolvimento de uma região é resultado de diferentes processos econômicos, sociais e políticos. Boisier (1996) argumenta que construir uma região significa potencializar sua capacidade de auto-organização, transformando uma sociedade adormecida diante das possibilidades, em uma sociedade ativa, organizada, capaz de criar e se mobilizar em prol do seu próprio desenvolvimento. Neste caso com base em forças endógenas, uma vez que o território não se relaciona, apenas, ao espaço físico, mas à proximidade, atores, interações e que atua ainda, "[...] como elemento crucial da matriz de relações que define a morfologia do poder nas sociedades contemporâneas" (REIS, 2015, p. 109).

Vázquez-Barquero (2014) evidencia a importância das estratégias das empresas para o desenvolvimento. Entre as características desse processo é a interação entre empresas e os demais atores locais, com o intuito de desenvolver a economia e a sociedade. Para o autor, as empresas influenciam no aumento da concorrência nos mercados e na busca de retorno dos investimentos, que as levam a adotarem novas tecnologias que utilizam melhor os recursos (inclusive intangíveis) e os atrativos (recursos específicos) das cidades e regiões.

Pensar o desenvolvimento pela perspectiva endógena, coloca a região como espaço de negociação e fator preponderante ao processo (FEGER; ETGES; ROSSETO, 2010). Filippim et al. (2014, p. 5) afirmam que “[...] o território local é importante arena para o debate e consolidação de soluções criativas e descentralização para problemas comuns, tanto para a gestão de políticas públicas quanto para o desenvolvimento [...]".

Assim sendo, entende-se que cada região necessita estabelecer os seus próprios mecanismos e parâmetros de desenvolvimento, sob pena de buscar (quase sempre), por aquilo que outras regióes já alcançaram. Ressalta-se que as regiões fazem parte de um todo, o que significa que mesmo com forte potencial endógeno, forças exógenas são necessárias para promoção do seu desenvolvimento, a exemplo dos repasses financeiros realizados pela União aos estados e aos municípios.

Os pequenos municípios, principalmente quando situados distantes de maiores centros urbanos, possuem maior dificuldade de visibilidade em suas iniciativas, pois são carentes de atividades industriais e de serviço, com predomínio de atividades de subsistência e forte dependência da agropecuária (SANTOS, 2003), o que provoca o deslocamento populacional e de capital. No entanto, as características socioeconômicas do entorno dos pequenos municípios, também precisam ser consideradas dentro do contexto socioeconômico microrregional, pois estes fatores exercem influência no seu desenvolvimento. Bernardy $(2013$, p. 6), relata que "[...] os aspectos socioespaciais dos munícipes são fortemente influenciados pela capacidade que os atores locais possuem em criar pactos entre os diferentes segmentos representativos”. Assim, a articulação entre sociedade, entidades representativas e poder público municipal, podem ser um instrumento promissor de desenvolvimento.

Além disso, Denardi et al. (2000) afirmam que a infraestrutura de transportes é vital para o desenvolvimento de municípios, especialmente os pequenos, pois o contexto socioeconômico é reflexo das condições estruturais para escoamento de sua produção e também do contexto socioeconômico microrregional, uma vez que a presença de eixos de transporte e entroncamento 
rodoviários, cidades polos, diversificação da produção, presença de agroindústrias e mercados, são fatores determinantes que afetam o desenvolvimento local.

No Brasil, a modalidade de transporte mais expressiva é a rodoviária, (PEREIRA; 2006). Essa infraestrutura de transporte e de qualidade, de acordo com Sánchez Hernández (1998), propicia condições que favorecem a dinâmica econômica dos municípios situados nas proximidades destes eixos. No entanto, o autor aponta que a rede rodoviária nacional se apresenta bastante deteriorada, com extensos trechos necessitando de expressivos e sistemáticos recursos para a sua recuperação.

Além disso, Pontes (1974) discorre que o desenvolvimento é obtido mediante propagação dos seus polos de desenvolvimento. Os polos exercem influência econômica e política sobre pequenas regiões periféricas (território-proximidade de acordo com a concepção de Reis, 2015). Entre um polo e outro é necessário que existam vias de ligação. Para Colling e Piffer (2016), estas vias podem ser caracterizadas como corredores ou eixos de desenvolvimento, uma vez que se deve considerar aspectos econômicos, geográficos e políticos. Desta forma, as cidades situadas ao longo destas vias podem se beneficiar justamente pela sua localização junto a tais eixos viários.

Por este motivo, cada município necessita agir de acordo com a sua realidade local, a fim de desenvolver políticas voltadas para potencializar o desenvolvimento com base na diversificação de atividades econômicas, melhoria da qualidade de vida, geração de emprego e renda, implantação de infraestrutura adequada, entre outras características que possibilitam a promoção do desenvolvimento.

\section{Procedimentos Metodológicos}

Este trabalho classifica-se como estudo multicaso por compreender como objeto duas microrregiões, situadas na mesorregião Oeste Catarinense: Chapecó, constituída por 38 municípios e São Miguel do Oeste constituído por 21 municípios. Na pesquisa, as microrregióes assumem a denominação de Microrregião 01 e Microrregião 02, respectivamente. Apresenta um enfoque quantitativo complementado pelos aspectos qualitativos, uma vez que seu desenvolvimento se deu por meio de levantamento e tratamento de dados secundários e, posteriormente, dados primários.

São aplicadas variáveis dependentes, independentes e intervenientes/moderadoras. Assumem o papel de variáveis independentes os Indicadores do Valor Adicionado Bruto (VAB) setorial e variação local da população: (i) VAB Agropecuária 2012 até 2016; (ii) VAB Indústria 2012 até 2016; (iii) VAB Serviços 2012 até 2016; (iv) Taxa de variação da população total 2012 até 2018.

O conjunto de receitas públicas desempenha a função de variável dependente, e compreende os seguintes dados do período de 2012 a 2018: (i) Receita Total; (ii) Receita Tributária; (iii) Receita de Contribuições; (iv) Receita Patrimonial; (v) Receita de Serviços; (vi) Transferências Correntes; (vii) Transferências de Capital; (viii) FPM.

Como variável moderadora, foi definido o acesso viário, uma vez que a capacidade de acesso para escoamento da produção local é realizada por este meio. Há um eixo principal de fluxo viário que é a rodovia federal BR 282, interligada por acessos secundários (rodovias de ligamento - federais e estaduais) e ainda municípios com conexão indireta, que para acessar a via principal dependem de outros meios de acesso. As Classificações dos municípios em função dos seus acessos estão descritos a seguir.

O levantamento dos dados secundários se deu por meio de bases oficiais no período de julho e agosto de 2019. O IBGE serviu como fonte para dados demográfico e dos VAB setoriais das microrregiões. O Tribunal de Contas do Estado de Santa Catarina (TCE/SC) e a Federação Catarinense dos Municípios (FECAM) constituíram as fontes dos dados financeiros e econômicos (receitas públicas - orçamento público) dos municípios. 
Figura 1. Microrregião 01 - Classificação dos municípios pela acessibilidade viária

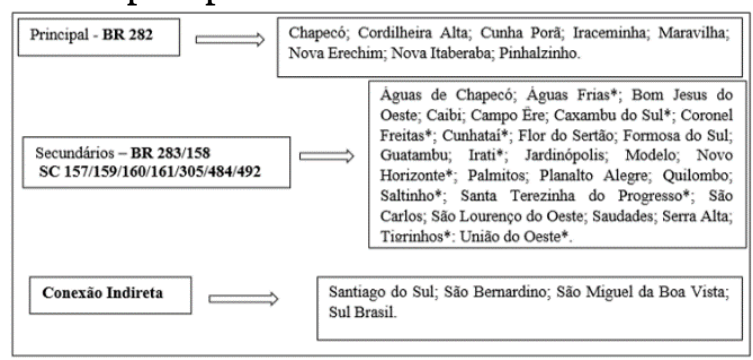

Fonte: Elaborado pela autora, 2019

*Presença de BR ou SC, no entanto, o acesso até o eixo principal (BR-282) acontece por intermédio de outros municípios.
Figura 2. Microrregião 02 - Classificação dos municípios pela acessibilidade viária

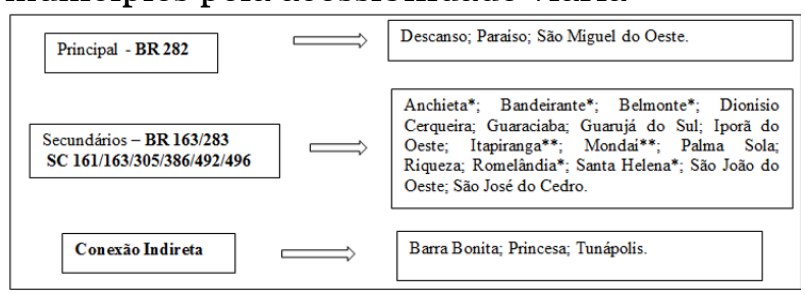

Fonte: Elaborado pela autora, 2019. * Presença de BR ou SC, no entanto, o acesso até o eixo principal (BR-282) acontece por intermédio de outros municípios.

** Presença de balsa de conexão interestadual (Rio Grande do Sul e Santa Catarina).

Os dados primários foram obtidos por meio de entrevista semiestruturada, nos quais foram visitados seis municípios, sendo três de cada microrregião. As visitas aconteceram nas datas de 31 de outubro e 01 de novembro de 2019, com agenda prévia. Para definição dos municípios visitados partiu-se, dos seguintes critérios: (a) acessibilidade viária deslocada do eixo principal - BR 282; (b) interesse e disponibilidade dos municípios contatados em contribuir com a pesquisa; (c) ser pequenos municípios; (d) presença de ambiente fronteiriço.

Foram entrevistados gestores públicos com cargo/função: Secretário da Fazenda e Administração; Secretário de Desenvolvimento Econômico; Secretário de Agricultura; Secretário de Finanças; e Prefeito Municipal. Assumem na pesquisa a seguinte denominação: Gestor A (Dionísio Cerqueira); Gestor B (São José do Cedro); Gestor C (Bandeirante); Gestor D (Quilombo); Gestor E (Formosa do Sul); e; Gestor F (Santiago do Sul). Apesar do baixo número de municípios visitados, as informações começaram a se repetir, deste modo, infere-se ter chegado à saturação teórico/empírica (NASCIMENTO et al., 2018).

Para elaboração do material de análise, aplicou-se fórmulas dinâmicas do software encontrando as médias de variação populacional, receitas e valor adicionado bruto (VAB) setorial. Com os dados quantitativos organizados optou-se em construir análises a partir da classificação em paineis divididos em quadrantes. A lógica da técnica aplicada para esta classificação foi exatamente a mesma para todos os quadrantes produzidos, de modo que foi detalhado apenas um processo, visto que a única variação para os demais acontece na mudança da tipologia da receita e não na técnica aplicada.

Para o cálculo da classificação por quadrante das transferências correntes em relação à receita total foi utilizada a média do período 2012 a 2018, uma vez que, quando calculado de forma individual (anual), observou-se que não houve expressivas oscilações. Desta forma, foi realizado o cálculo da média do percentual de dependência (Mpd) da seguinte forma: somou-se as receitas de transferências correntes de todos os anos, dividiu-se pelas receitas totais também de todos os anos e multiplicou-se por cem, ou seja, Mpd = (TC 2012 a 2018) / (RT 2012 a 2018) x 100. Com este cálculo foi encontrada a média representativa das transferências correntes em relação à receita total. No Excel, com uso da ferramenta de filtro, ordenou-se do menor para o de maior percentual de dependência. Para maior precisão classificatória, foi deduzido do maior percentual de transferência corrente pelo menor percentual e, deste resultado encontrado, dividiu-se por 4, originando o recorte de classificação no quadrante.

\section{Discussão e análise dos resultados}

O ambiente da pesquisa, constituído pelas microrregióes 01 e 02 , com característica predominante de pequenos municípios, possuem um polo de desenvolvimento (Chapecó - cidade média) e três micropolos (Pinhalzinho, Maravilha e São Miguel do Oeste - cidades medianas). A classificação de acessibilidade viária serve como elemento para o comportamento dos grupos de análise dos itens variação populacional), variação da receita total e subgrupos receitas tributárias e transferências correntes e das receitas do Fundo de Participação dos Municípios (FPM). 
Tabela 1: Classificação pela acessibilidade viária

\begin{tabular}{|c|c|c|}
\hline \multicolumn{2}{|c|}{ Acessibilidade Viária } & Descrição de Municípios \\
\hline \multirow{2}{*}{ Principal } & Micro 01 & $\begin{array}{l}\text { Chapecó; Cordilheira Alta; Cunha Porã; Iraceminha; Maravilha; } \\
\text { Nova Erechim; Nova Itaberaba; Pinhalzinho. }\end{array}$ \\
\hline & Micro 02 & Descanso; Paraíso; São Miguel do Oeste. \\
\hline \multirow[t]{2}{*}{ Secundário } & Micro 01 & $\begin{array}{l}\text { Águas de Chapecó; Águas Frias; Bom Jesus do Oeste; Caibi; } \\
\text { Campo Êre; Caxambu do Sul; Coronel Freitas; Cunhataí; Flor do } \\
\text { Sertão; Formosa do Sul; Guatambu, Irati; Jardinópolis; Modelo; } \\
\text { Novo Horizonte; Palmitos; Planalto Alegre; Quilombo; Saltinho; } \\
\text { Santa Terezinha do Progresso; São Carlos; São Lourenço do } \\
\text { Oeste; Saudades; Serra Alta; Tigrinhos; União do Oeste. }\end{array}$ \\
\hline & Micro 02 & $\begin{array}{l}\text { Anchieta; Bandeirante; Belmonte; Dionísio Cerqueira; Guaraciaba; } \\
\text { Guarujá do Sul; Iporã do Oeste; Itapiranga; Mondaí; Palma Sola; } \\
\text { Riqueza; Romelândia; Santa Helena; São João do Oeste; São } \\
\text { José do Cedro; }\end{array}$ \\
\hline \multirow{2}{*}{$\begin{array}{l}\text { Conexão } \\
\text { Indireta }\end{array}$} & Micro 01 & $\begin{array}{l}\text { Santiago do Sul; São Bernardino; São Miguel da Boa Vista; Sul } \\
\text { Brasil. }\end{array}$ \\
\hline & Micro 02 & Barra Bonita; Princesa; Tunápolis. \\
\hline
\end{tabular}

\section{Análise da variação populacional}

A análise da distribuição populacional de um território permite desenhar cenários do seu dinamismo demográfico. Sob a ótica comportamental, em ambas as microrregiões são encontrados os mesmos padrões, ou seja, ganho populacional em municípios com acessibilidade principal e secundária e perda populacional em municípios com conexões indiretas.

Tabela 2: Variação populacional (2012-2018)

\begin{tabular}{cll}
\hline Microrregião & Acessibilidade viária & Média por categoria \\
\hline \multirow{2}{*}{ Micro 01 } & Principal - BR 282 & $13,26 \%$ \\
\cline { 2 - 3 } & Secundários & $0,66 \%$ \\
\cline { 2 - 3 } Micro 02 & Conexão Indireta & $(-8,07)$ \\
\cline { 2 - 3 } & Principal - BR 282 & $0,86 \%$ \\
\cline { 2 - 3 } & Secundários & $1,71 \%$ \\
\cline { 2 - 3 } & Conexão Indireta & $(-0,75)$ \\
\hline
\end{tabular}

Fonte: adaptado do IBGE, $2012-2018$

Na microrregião 01, observa-se que a acessibilidade viária principal - BR 282 exerce forte influência quanto à atratividade populacional, visto que, para o período 2012-2018, sua população cresceu em 13,26\%, o que constitui um indicador de desenvolvimento, embora seja de variação moderada. No entanto, na microrregião 02, o elemento acesso viário (principal - BR 282) não exerce a mesma influência: se explica devido ao fato do acesso viário não ser o único fator considerado para o desenvolvimento territorial.

Sanchez Hernández (1998), Sposito; Matushima (2002) e Bordo (2006) afirmam que a presença de infraestrutura de transportes e de qualidade e a industrialização são características de eixos de desenvolvimento. Na microrregião 01, situa-se Chapecó que exerce acentuada influência como polo regional. Pinhalzinho e Maravilha, dois micropolos, que possuem forte presença industrial, o que, na visão de Bordo (2006) propicia condições mais favoráveis para a dinâmica econômica e desenvolvimento do território. Estes fatores, indicam uma possível justificativa para a concentração migratória para a microrregião 01 e não para a 02.

Nos municípios com acesso viário de conexão indireta, registra-se perda populacional em ambas as microrregiões. Ferreira (2006) afirma que a falta de infraestrutura e logística favorável ao desenvolvimento de atividades econômicas, exercem forte impacto negativo nos territórios. Além disso, Pereira e Lessa (2011) defendem que a carência de planejamento no setor de transportes pode trazer prejuízos aos territórios e reforçar desequilíbrios regionais.

\section{Análise espacial da variação da receita total}

A tabela 3 apresenta a classificação dos municípios das microrregiões 01 e 02 , pelo seu percentual de variação da receita total, no período do estudo (2012 - 2018), categorizado em 
quadrantes em relação à sua acessibilidade viária. Observa-se que os municípios com acesso viário principal - BR 282 (variável moderadora) apresentaram melhor desempenho, em relação aos demais acessos, visto que o menor, deste grupo, foi de $31,74 \%$ (quadrante 2) e o maior 48,28\% (quadrante 4). A concentração dos municípios desta categoria está nos quadrantes 3 e 4 e nenhum no quadrante 1. Neste grupo, encontram-se o polo Chapecó e os micropolos Pinhalzinho, Maravilha e São Miguel do Oeste. Massardi; Abrantes (2014) e Reis (2015) afirmam que as regiões mais desenvolvidas possuem maior dinamicidade e atratividade econômica, mobilidade e fluidez de pessoas, como consequência, maior geração de receita públicas.

Tabela 3: Percentual de Crescimento da receita total por acessibilidade

\begin{tabular}{|c|c|c|c|c|}
\hline Quadrante & $\%$ Crescimento RT & Principal - BR 282 & Secundário & $\begin{array}{l}\text { Conexão } \\
\text { Indireta }\end{array}$ \\
\hline 1 & $20,37 \%$ a $27,34 \%$ & & Dionísio Cerqueira; Serra Alta. & Sul Brasil. \\
\hline 2 & $27,35 \%$ a $34,32 \%$ & Nova Itaberaba. & $\begin{array}{l}\text { Águas de Chapecó; Águas Frias*; } \\
\text { Belmonte *; Campo Êre; Caxambu do } \\
\text { Sul*; Coronel Freitas*; Cunhataí*; }^{*} \text { ' } \\
\text { Jardinópolis; Novo Horizonte*; Palma } \\
\text { Sola; Palmitos; Planalto Alegre; } \\
\text { Quilombo; Riqueza; Saltinho*; Santa } \\
\text { Terezinha do Progresso*; São } \\
\text { Lourenço do Oeste; Tigrinhos*; União } \\
\text { do Oeste*. }\end{array}$ & $\begin{array}{l}\text { Barra Bonita; } \\
\text { Princesa; } \\
\text { Santiago do } \\
\text { Sul; São } \\
\text { Bernardino; } \\
\text { São Miguel da } \\
\text { Boa Vista. }\end{array}$ \\
\hline 3 & $34,33 \%$ a $41,30 \%$ & $\begin{array}{l}\text { Cunha Porã; Chapecó; } \\
\text { Iraceminha; Descanso; } \\
\text { São Miguel do Oeste. }\end{array}$ & $\begin{array}{l}\text { Anchieta*; Bandeirante*; Bom Jesus } \\
\text { do Oeste; Caibi; Flor do Sertão; } \\
\text { Formosa do Sul; Guarujá do Sul; Iporã } \\
\text { do Oeste; Itapiranga*; Modelo; } \\
\text { Mondai**; Romelândia*; Santa } \\
\text { Helena*; São Carlos; São João do } \\
\text { Oeste; São José do Cedro; }\end{array}$ & Tunápolis. \\
\hline 4 & $41,31 \%$ a $48,28 \%$ & $\begin{array}{l}\text { Paraíso; Pinhalzinho; } \\
\text { Nova Erechim; } \\
\text { Cordilheira Alta; } \\
\text { Maravilha. }\end{array}$ & $\begin{array}{l}\text { Guaraciaba; Guatambu*; Irati*; } \\
\text { Saudades. }\end{array}$ & \\
\hline
\end{tabular}

Os municípios com acesso viário secundário (variável moderadora) tiveram seu crescimento de receita total concentrados nos quadrantes 2 e 3, ou seja, intermediários e os de conexão indireta não têm nenhum ente no quadrante 4. Estas constatações corroboram com Ferreira (2006) que menciona as interações entre territórios polo, centralizadores de fluxo e territórios periféricos, ou seja, pertencentes a mesma microrregião ou região.

O autor defende que normalmente estas interações são desiguais, sendo favoráveis aos polos uma vez que recebem fluxos de maior intensidade que os que enviam aos territórios sob sua influência. Além disso, a acessibilidade viária exerce influência de atratividade e dinamismo econômico, ao considerar que o escoamento da produção do ambiente é realizado, exclusivamente, por eixo rodoviário.

Destaca-se que não houve perda de receita, mas crescimento em todos os municípios de ambas as microrregiões. Esse comportamento se justifica pelo acréscimo da receita proveniente dos tributos de competência própria dos municípios (assimétricas nas microrregiões) e, devido ao aumento das transferências intergovernamentais repassadas aos municípios, também acompanhada pelo aumento da responsabilidade na execução de políticas públicas (MASSARDI; ABRANTES, 2014).

\section{Análise das receitas tributárias e transferências correntes}

Para a construção do quadro, a lógica da classificação de receita tributária e de receita de transferências correntes foi invertida. Na receita tributária os quadrantes foram classificados em ordem crescente de representatividade em relação à receita total. Já na receita de transferências correntes os quadrantes são do maior para o menor percentual de representatividade em relação à receita total, uma vez que a finalidade foi colocar lado a lado para verificar, se, os municípios do 
grupo de menor receita tributária, são os mesmos municípios que possuem maior dependência de transferências correntes.

Quanto à classificação com base nas receitas tributárias, dos 38 municípios da microrregião 01 e dos 21 municípios da microrregião $02,65,79 \%$ e 61,90\%, respectivamente, estão no quadrante 1 . Esta constatação demonstra que a debilidade quanto à geração de receita própria não é particularidade de uma ou de outra microrregião. Afinal, conforme discorre Abrucio; Couto (1996) é característica de pequenos municípios possuir uma base econômica eminentemente agropecuária, portanto, os rendimentos tributáveis são poucos representativos.

Constatou-se que os municípios que apresentaram melhor desempenho não superaram os 23\% de geração de receita própria em relação à sua receita total. O melhor desempenho foi apurado no polo regional Chapecó, com 22,94\%, seguido pelos micropolos São Miguel do Oeste com 20,02\%, Pinhalzinho com 17,07\% e Maravilha com 16,44\%. Embora insuficientes para mantenimento da estrutura pública, o desempenho superior em relação aos demais municípios, decorre da dinamicidade de atividades econômicas, propagação dos polos de desenvolvimento e influência socioeconômica que estes exercem sobre territórios periféricos. Em complemento aos elementos de análise é validada, nestes municípios, a inferência classificatória dos quadrantes, uma vez que o polo e micropolos se enquadraram nos quadrantes 3 e 4, tanto para as receitas tributárias quanto para as receitas de transferências correntes.

Em contrapartida, $66,10 \%$ dos municípios geraram menos de $8 \%$ da sua receita própria, evidenciando a dependência crônica de receitas intergovernamentais, uma vez que os integrantes do quadrante 1 de receita tributária, 74,35\% têm sua receita total constituída em aproximadamente $90 \%$ de transferências correntes (para este cenário a inferência, também se confirmou). São pequenos municípios que em sua maioria passam pelo processo de retração populacional e sua acessibilidade viária é superior a 70\% secundária, seguida por aproximadamente $18 \%$ com conexão indireta.

Santos (2003) avalia que os pequenos municípios, principalmente quando deslocados de corredores de fluxos de desenvolvimento (COLLING; PIFFER, 2016) têm menor visibilidade quanto às suas iniciativas, pois a carência de atividades industriais, com predomínio de atividades de subsistência e forte dependência de atividades primárias, resulta no deslocamento populacional para territórios mais desenvolvidos, que possuem suas bases econômicas mais favoráveis para a geração de oportunidades de trabalho e renda.

A autonomia dos municípios prevista na Constituição, não se confirma no ambiente, uma vez que, $49,15 \%$ dos municípios encontram-se no quadrante 1 das transferências correntes: têm praticamente $90 \%$ de sua receita total oriunda de transferências intergovernamentais. O FPM se constitui o principal repasse advindo da União, seguido pelo quadrante 2 de, aproximadamente $82 \%$ com $35,60 \%$ dos municípios enquadrados neste. Juntos, quadrante 1 e 2 , representam $84,75 \%$ dos municípios 1 da pesquisa. Neste cenário de dependência de recursos para o orçamento público fica evidente o indicativo da fragilidade das bases econômicas de um ente administrativo, de modo que existe uma relação direta entre as atividades econômicas com capacidade de geração de receitas, sucedidas dos tributos (Tabela 4 ).

\section{Análise das receitas do Fundo de Participação dos Municípios (FPM)}

O processo de isolamento da variável dependente, em relação a outras variáveis dependentes teve a finalidade de mensurar o impacto do FPM, sua significância para o orçamento público municipal, uma vez que os municípios são responsáveis por disponibilizar serviços públicos, além de promover políticas que visem melhores condições, qualidade de vida e desenvolvimento socioeconômico em seus territórios (SANTOS; SANTOS, 2014).

Quanto às transferências correntes, o FPM representa de $15,84 \%$ a $69,02 \%$ do total de repasses intergovernamentais, e quanto à receita total, esta transferência representa de 9,66\% a $59,79 \%$. Este cenário significa que nas microrregiões, assim como a maioria dos municípios brasileiros, em $81 \%$, o FPM é a principal fonte de recursos e sua forma de partilha per capita entrega mais recursos para municípios com menor população (TRISTÃO, 2003) 
Tabela 4: Representatividade de receita tributária e receita de transferência corrente em relação à receita total e acessibilidade viária

\begin{tabular}{|c|c|c|c|c|c|}
\hline $\begin{array}{l}\text { Receita } \\
\text { Tributária } \\
\text { (\%) }\end{array}$ & Municípios & Acessibilidade & $\begin{array}{c}\text { Receita de } \\
\text { Transferências } \\
\text { Correntes (\%) }\end{array}$ & Municipios & Acessibilidade \\
\hline \multirow[b]{3}{*}{2,66 a 7,72} & \multirow{3}{*}{$\begin{array}{l}\text { Santa Helena; São Bernardino; Santa } \\
\text { Terezinha do Progresso; Bandeirante; } \\
\text { Irati; Sul Brasil; Santiago do Sul; Barra } \\
\text { Bonita; Princesa; Cunhataí; Belmonte; } \\
\text { São Miguel da Boa Vista; Jardinópolis; } \\
\text { Tigrinhos; Planalto Alegre; Águas Frias; } \\
\text { União do Oeste; Bom Jesus do Oeste; } \\
\text { Flor do Sertão; Saltinho; Paraíso; } \\
\text { Tunáaolis; Iraceminha; Nova Itaberaba; } \\
\text { Águas de Chapecó; Caxambu do Sul; } \\
\text { Formosa do Sul; Riqueza Romelândia } \\
\text { Serra Alta; Modelo; Anchieta; Nova } \\
\text { Erechim; Palma Sola; Guarujá do Sul; } \\
\text { Caibi; Guatambu; Mondai. (66,10\%). }\end{array}$} & Principal BR 282: 10,26\%. & \multirow[b]{3}{*}{81,90 a 88,90} & \multirow{3}{*}{$\begin{array}{l}\text { Caibi; Saltinho; Planalto Alegre; } \\
\text { Romelândia; Jardinópolis; } \\
\text { Formosa do Sul; Princesa; } \\
\text { Mondai; Águas de Chapecó; } \\
\text { União do Oeste; Belmonte; } \\
\text { Iraceminha; Nova Itaberaba; } \\
\text { Tigrinhos; Cunhataí; Guatambu; } \\
\text { Irati; Barra Bonita; São } \\
\text { Bernardino; Bom Jesus do } \\
\text { Oeste; Caxambu do Sul; } \\
\text { Santiago do Sul; Santa Terezinha } \\
\text { do Progresso; São Miguel da Boa } \\
\text { Vista; Águas Frias; Paraíso; } \\
\text { Santa Helena; Bandeirante; Flor } \\
\text { do Sertão. (49,15\%). }\end{array}$} & Principal BR 282: 10,34\% \\
\hline & & Secundário: $\mathbf{7 1 , 7 9 \% .}$ & & & Secundário: $\mathbf{7 2 , 4 2 \%}$ \\
\hline & & Conexão Indireta: $\mathbf{1 7 , 9 5 \% . ~}$ & & & Conexão Indireta: $\mathbf{1 7 , 2 4 \%}$ \\
\hline \multirow{3}{*}{7,73 a 12,79} & \multirow{3}{*}{$\begin{array}{l}\text { Quilombo; Saudades; Guaraciaba; } \\
\text { Campo Ête; Cordilheira Alta; Descanso; } \\
\text { Dionísio Cerqueira; São Carlos; São José } \\
\text { do Cedro; Coronel Freitas; São João do } \\
\text { Oeste; Palmitos; Iporã do Oeste; Cunha } \\
\text { Porã; Itapicanga; São Lourenço do Oeste. } \\
\mathbf{( 2 7 , 1 2 \% )}\end{array}$} & Principal BR 282: $\mathbf{1 8 , 7 5 \% . ~}$ & \multirow{3}{*}{74,93 a 81,89} & \multirow{3}{*}{$\begin{array}{l}\text { São Lourenço do Oeste; Palmitos; } \\
\text { Campo Êre; Saudades; Modelo; } \\
\text { São Carlos; Palma Sola; } \\
\text { Guaraciaba; Iporã do Oeste; } \\
\text { Cordilheira Alta; Serra Alta; Nova } \\
\text { Erechim; Cunha Porã; Sul Brasil; } \\
\text { Quilombo; Descanso; São João } \\
\text { do Oeste; Junápolis; Guarujá do } \\
\text { Sul; Anchieta; Riqueza. (35,60\%). }\end{array}$} & Principal BR 282: $19,05 \%$ \\
\hline & & Secundário: $\mathbf{8 1 , 2 5 \% .}$ & & & Secundário: $\mathbf{7 1 , 4 3 \%}$ \\
\hline & & Conexão Indireta: (0\%). & & & Conexão Indireta: $\mathbf{9 , 5 2 \%}$ \\
\hline \multirow{3}{*}{12,80 a 17,86} & \multirow{3}{*}{ Maravilha; Pinhalzinho. (3,39\%). } & Principal BR 282: $\mathbf{1 0 0 \% .}$ & \multirow{3}{*}{67,96 a 74,92} & \multirow{3}{*}{$\begin{array}{lrr}\text { Maravilha; } & \text { Coronel } & \text { Freitas; São } \\
\text { José do } & \text { Cedro; } & \text { Pinhalzinho; } \\
\text { Itapicanga; } & \text { Novo } & \text { Horizonte. } \\
(\mathbf{1 0 , 1 7 \% )} & & \end{array}$} & Principal BR 282: $\mathbf{3 3 , 3 3 \%}$ \\
\hline & & Secundário: $\mathbf{0} \%$. & & & Secundário: $66,67 \%$ \\
\hline & & Conexão Indireta: $\mathbf{0} \%$. & & & Conexão Indireta: $\mathbf{0} \%$ \\
\hline \multirow{3}{*}{17,87 a 22,94} & \multirow{3}{*}{ São Miguel do Oeste; Chapecó. (3,39\%). } & Principal BR 282: $\mathbf{1 0 0 \% .}$ & \multirow{3}{*}{60,99 a 67,95} & \multirow{3}{*}{$\begin{array}{l}\text { Chapecó; Dionísio Cerqueira; São } \\
\text { Miguel do Oeste. }(\mathbf{5 , 0 8 \% )} \text {. }\end{array}$} & Principal BR 282: $66,67 \%$ \\
\hline & & Secundário: $\mathbf{0} \%$. & & & Secundário: $\mathbf{3 3 , 3 3 \%}$ \\
\hline & & Conexão Indireta: $\mathbf{0} \%$. & & & Conexão Indireta: $\mathbf{0 \%}$ \\
\hline
\end{tabular}

A análise permite confirmar que dos quadrantes relacionados (receita de TC e receita total) os municípios que compõe cada qual são, na maioria, os mesmos, ou seja, que ocupam o quadrante 1 de transferência corrente, também ocupam o quadrante 1 de receita total e assim sucessivamente, com poucas exceções. O município de Chapecó, o polo da microrregião 01, possui o menor percentual de FPM em relação ao seu orçamento de receita total, $(9,66 \%)$, seguido por São Lourenço do Oeste (20,30\%), São Miguel do Oeste - micropolo (20,54\%) e Itapiranga (21,22\%).

O quadrante 4 apresenta constatações alarmantes, pois, o FPM representa $47,25 \%$ a $59,79 \%$ da receita total, de 17 municípios (do total de 59), ou seja, 28,81\% integram este bloco, sendo que destes, 15 são municípios da microrregião 01. Este quadrante é constituído por "jovens pequenos municípios”, uma vez que todos eles foram constituídos após a Constituição Federal de 1988.

O FPM representa para $54,24 \%$ dos municípios, deste ambiente, mais de $40 \%$ de sua receita total, seguido de mais de $50 \%$ para $28,81 \%$ dos municípios. Entre os municípios mais dependentes do FPM (acima de 50\%), estão: São Miguel da Boa Vista (59,79\%), seguido por Santiago do Sul (município que sofreu maior perda de população no estado de Santa Catarina, de acordo com estimativa IBGE 2019), Barra Bonita, Irati, Cunhataí, Tigrinhos, Flor do Sertão, Santa Terezinha do Progresso, Jardinópolis, Santa Helena e Bom Jesus do Oeste.

\section{Análise do valor adicionado bruto (VAB)}

A tabela 5 apresenta o desempenho do VAB agropecuário, indústria, serviços privados e públicos do grupo de municípios em conformidade com a acessibilidade viária. A finalidade deste é analisar se, de fato, o posicionamento geográfico, vias de acesso, fluxo e escoamento produtivo, proximidade e infraestrutura, conforme as concepções de Romanatto et al. (2015), são fatores de influência na dinamicidade das atividades econômicas, nas microrregiões 01 e 02. Para identificação da tipologia de acesso de cada município a tabela 1 (Classificação pela Acessibilidade Viária) serve de referência. 
Tabela 5: VAB setorial por acessibilidade viária

\begin{tabular}{lllll}
\hline $\begin{array}{l}\text { Acessibilidade } \\
\text { viária }\end{array}$ & VAB_Agro & VAB_Indústria & VAB_Serviços & VAB_Ser.Públicos \\
\hline Principal - BR 282 & $5,28 \%$ & $29,40 \%$ & $53,51 \%$ & $11,81 \%$ \\
\hline Secundários & $23,70 \%$ & $23,13 \%$ & $37,20 \%$ & $15,97 \%$ \\
\hline Conexão Indireta & $39,27 \%$ & $12,50 \%$ & $24,23 \%$ & $24,00 \%$ \\
\hline
\end{tabular}

Evidencia-se que as atividades econômicas de maior valor agregado, mais "nobres" estão situadas no eixo de acesso viário principal - BR 282, uma vez que os serviços privados e a indústria exercem forte representatividade. No grupo, os serviços privados e a indústria apresentaram melhor desempenho, $53,51 \%$, e $29,40 \%$, respectivamente.

A presença de complexos agroindustriais de significativa relevância em municípios deste grupo, fomentam o crescimento e desenvolvimento da atividade econômica de serviços, uma vez que são atividades complementares, além de influenciar na atratividade populacional, pelas oportunidades de trabalho e renda. Por meio destes percentuais conclui-se, também, que para a atividade industrial o fator locacional é determinante, de modo que escoar a produção para mercados consumidores requer infraestrutura de transporte rodoviário, é a seletividade espacial consideradas pelas firmas, na atualidade.

Para os municípios com acessibilidade por meio de conexão indireta o VAB agropecuário é representativo. Este grupo é constituído por pequenos e "jovens municípios" que apresentam retração populacional, crônica dependência de transferências intergovernamentais, portanto, receita tributária baixíssima: variação de $2 \%$ a $5 \%$ em relação à receita total.

Para os municípios categorizados no acesso viário secundário, evidencia-se maior equilíbrio entre os VABs setoriais presentes neste grupo, com destaque ao VAB serviços privados, 37,20\%. Essa condição reflete a proximidade a polos e micropolos que promovem atratividade de atividades complementares às localizadas nestes centros urbanos. Além disso, por ter integrados neste grupo, pequenos municípios, com características similares ao acesso de conexão indireta, o VAB agropecuário apresenta expressivo desempenho.

Em uma análise de forma natural, em parte centrada no senso comum, existe a perspectiva de entendimento que os territórios possuem condições igualitárias de desenvolvimento, situação não cristalizada nos distintos níveis de produção do espaço. Muitos municípios pequenos, possuem uma conjuntura de desenvolvimento "condicionada" e confinada aos elementos naturais e humanos que são de difícil reversão, seja da paisagem física, como áreas declivosas ou inaptas para a produção e desenvolvimento de matrizes econômicas, seja pelos recursos infraestruturais, econômicos e financeiros limitados. Estes municípios quando difundidos pelo território se constituem como áreas de desvitalização e depressão econômica, com expressivos reflexos sociais, as vezes acrescidos pelo isolamento geográfico e fazem parte da exclusão territorial do desenvolvimento, que é seletivo.

\section{Análise de dados primários}

Por se tratar de uma região fronteiriça, Dionísio Cerqueira (Santa Catarina, Brasil) e Bernardo de Irigoyen (Misiones, Argentina) ficou evidente que a infraestrutura aduaneira, por si só, não representa um elemento catalisador do desenvolvimento, uma vez que serve apenas como um ponto de passagem e fluxo de usuários, sem impactar de forma determinante no desenvolvimento econômico do município.

A presença de infraestrutura viária, na concepção de Vázquez-Barquero (2014), é um vetor básico para o desenvolvimento. Este elemento é encontrado no município de Bandeirante (microrregião 02), no qual a descentralização de atividade econômica industrial da cidade mediana do micropolo - São Miguel do Oeste, só foi possível em função da infraestrutura de acesso viário (pavimentação asfáltica) e da proximidade de ambos os centros (COLLING; PIFFER, 2016).

Além disso, existe a "falsa" concepção que para promover desenvolvimento, às atividades industriais necessitam estar presente de forma física no território, especialmente, dos pequenos municípios. No caso específico das microrregiões existe uma desterritorialização do trabalhador, urbano e rural, uma vez que se movimentam desconsiderando os limites territoriais de seu município, situação comum para a empregabilidade nas agroindústrias. Exemplo de grande agroindústria que se localiza no município de Quilombo, com sua base de funcionários também dos municípios do entorno, entre eles, Formosa do Sul e Santiago do Sul. 
O município de São José do Cedro, apresentou uma característica peculiar, uma vez que sua base industrial é constituída por pequenas e médias empresas locais, muitas delas complementares às atividades rurais. Esta característica proporciona aos gestores públicos, a segurança quanto a não serem dependentes de grandes empresas, que em momentos de adversidade, a saída poderia refletir em um enorme impacto negativo no município, inclusive nas receitas públicas.

Quanto à relação dos pequenos municípios com a cidade polo existe a falsa ideia de uma convergência simétrica iminentemente no interior do estado, ou seja, que todos os municípios se relacionam com a cidade de Chapecó. Conforme respostas do Gestor A e C, esta afinidade não é integralmente percebida, pois determinados municípios criam vínculos nos serviços com cidades polos de outros estados: municípios do extremo oeste catarinense que possuem vínculos de atendimento de saúde com a cidade de Cascavel, no Paraná, inclusive, por meio de uma relação institucionalizada por convênio. Esta relação territorial também é impulsionada pela facilidade de acessos e dos fluxos viários.

Quanto à limitada capacidade de os entes municipais arrecadarem tributos próprios se destaca a precariedade na cobrança de impostos relacionados ao uso do solo urbano, neste caso, o IPTU. Observou-se, ser unanimidade entre os gestores a desatualização da planta de valores genéricos e deficiência na efetividade da cobrança sistemática deste tributo, o que se constituem uma evasão fiscal.

Esta leitura do cenário também tratou sobre as questões de variação populacional que se identificou a partir da análise dos dados secundários. Embora os gestores contestam os dados oficiais de estimativa populacional do IBGE, reconheceram, de forma unânime, que a variação, estagnação e retração populacional nos municípios se deve à saída do jovem em busca de oportunidade de continuidade nos estudos e integração no mercado de trabalho em centros maiores, como Chapecó e cidades medianas de referência.

Por fim, se identificou que um dos fatores para este cenário, de acordo com os entrevistados, está na dificuldade da sucessão familiar que acaba por desestimular o jovem a permanecer na propriedade rural e dar continuidade com a atividade desenvolvida pela família. Para esta situação, ficou evidente a oportunidade que os municípios possuem de atuar neste campo, uma vez que o acompanhamento por profissionais de áreas específicas poderia reduzir este impacto negativo e tornar esse processo de sucessão familiar natural, além de fortalecer vínculos familiares, permitiria também a valorização do segmento econômico da família.

\section{Conclusão da Pesquisa}

A relevância desta pesquisa está ancorada na contribuição para o desenvolvimento regional, equalização dos recursos públicos, além de produzir elementos que possam contribuir com os gestores municipais, uma vez que a investigação local é similar à realidade encontrada em outras regiões do Brasil, inclusive de forma sistemática e pulverizada no território.

$\mathrm{Na}$ análise dos quadrantes, em paineis, quanto às receitas: total, tributária e de transferências correntes em relação ao acesso viário, se observou melhor desempenho para os municípios com acesso principal - BR 282, tanto na geração de sua receita própria, quanto da menor dependência de transferências intergovernamentais (a terminologia "menor" não anula o seu, ainda, considerável percentual de dependência, apenas demonstra que em relação aos demais, sua dependência é reduzida).

Notou-se que os pequenos municípios, com acesso viário secundário e de conexão indireta possuem a maior dependência de transferência corrente, atingindo até $88,90 \%$ em relação a sua receita total. Para $28,81 \%$ dos municípios, o FPM, representou mais de $50 \%$ de suas receitas totais o que desencadeia restrições quanto ao avanço e efetividade do desenvolvimento econômico dos municípios, com base em suas matrizes econômicas.

A receita tributária que proporcionaria aos municípios a autonomia político-administrativa, não supera os $23 \%$ em todo o ambiente, sendo que nos municípios de conexão indireta e acesso secundário varia de $2,66 \%$ a 12,80\%, apenas. Portanto, é praticamente insignificativo no conjunto das receitas e também tem relação com as principais tipologias econômicas instaladas.

Em se tratando da dinamicidade socioeconômica dos municípios a estrutura viária é fator de forte influência para o desenvolvimento regional, considerado um elemento essencial e primário, visto que sua dinamicidade econômica se torna um vetor de atração populacional em busca de qualidade de vida. A forte segmentação da indústria e de serviços - privados e públicos - no grupo de acesso viário principal - BR 282, demonstra a criação de nichos econômicos em função do eixo 
para escoamento produtivo e pela própria rede de desenvolvimento criada em função da presença deste tipo de infraestrutura.

Os pequenos municípios têm acentuada dificuldade de impulsionar o desenvolvimento do seu território. $\mathrm{O}$ posicionamento geográfico, com acesso secundário e/ou conexão indireta predomina a atividade econômica agropecuária, de baixa adição de valor e de capacidade geradora de impostos. Apresentam acentuada retração populacional, que ocorre de forma natural e contínua. A homogeneização econômica, cristalizada em diferentes temporalidades, faz com que estes municípios fiquem à margem dos processos de desenvolvimento mais consolidados que acontecem de forma pontual e linear nas microrregiões, portanto, se encontram aprisionados aos processos de desenvolvimento regional.

Por fim, evidencia-se a ausência de sinergia e a fragilidade das atividades econômicas, nos pequenos municípios, visto que as receitas próprias resultam das tipologias econômicas desenvolvidas no território. Complementar à ausência e/ou carência de sinergia dos fatores apontados, a pesquisa identificou que a busca por alternativas de desenvolvimento é controversa, uma vez que nem todas as atividades econômicas podem ser replicadas em diferentes territórios.

\section{Referências}

ABRUCIO, F. L.; COUTO, C. G. A redefinição do papel do Estado no âmbito local. São Paulo em Perspectiva. São Paulo, v. 10, n.3, p.40-47, Jul./Set.1996, 1996.

ARRAIS, T. P. A. As receitas públicas municipais e a funcionalidade da integração espacial em ambientes metropolitanos. Revista Sociedade \& Natureza, v. 26, n. 2, 2014.

BARQUERO, A. V. Os territórios innovadores: espaços estratégicos do desenvolvimento. Revista Crítica e Sociedade, v. 4, n. 2, p. 52-71, 2014.

BATISTA, M. Burocracia local e qualidade da implementação de políticas descentralizadas: uma análise da gestão de recursos federais pelos municípios brasileiros. 2014.

BERNARDY, R. O Planejamento Urbano de Pequenos Municípios com Base no Plano Diretor. Desenvolvimento em Questão, 11(22), 4-34. https://doi.org/10.21527/2237-6453.2013.22.434, 2013.

BOISIER, S. Desarrollo territorial y descentralización: el desarrollo en el lugar y en las manos de la gente. Eure (Santiago), v. 30, n. 90, p. 27-40, 2004.

BORDO, A. A. As influências do eixo de desenvolvimento da Rodovia Washington Luiz na estruturação econômica do município de Itápolis/SP, 2006.

BOVO, J. M. Gastos sociais dos municípios e desequilíbrio financeiro. Revista de Administração Pública, v. 35, n. 1, p. 93-117, 2001.

CNM - CONFEDERAÇÃO NACIONAL DE MUNICÍPIOS. Finanças: Procedimentos para otimizar a arrecadação municipal. Brasília: CNM, 2012.

COLLING, M. A.; PIFFER, M. Corredores de desenvolvimento: conceito e aplicação. Desenvolvimento em Questão, 14(36), 99-134, 2016.

DENARDI, R. A., et al. (2000). Fatores que afetam o desenvolvimento local em pequenos municípios do Estado do Paraná. Curitiba: Emater-PR, 2000.

DA SILVA, F. J.; DE OLIVEIRA ROCHA, I. Emancipação municipal em Santa Catarina. Geosul, v. 27, n. 53, p. 115-138, 2012.

FEGER, J. E.; ETGES, V. E.; ROSSETTO, A. M. Limites de regionalizações para elaboração de estratégias para o desenvolvimento regional. Revista Gestão. Org, v. 8, n. 2, p. 172-192, 2010. 
FERREIRA, E. O. Desenvolvimento de sistema de indicadores de avaliação da infraestrutura rodoviária no contexto do desenvolvimento regional. 2006.

FIGUEIREDO, M. D.; LEITE, E. F. Cidades empreendedoras: as novas visões sobre planejamento urbano e desenvolvimento econômico no Brasil. REAd. Revista Eletrônica de Administração, v. 12, n. 5, p. 266-291, 2006.

FILIPPIM, E. S. et al. Cooperação Transfronteiriça para o Desenvolvimento Regional. Desenvolvimento em Questão, 12 (26), 5-40, 2014.

FIRJAN - FEDERAÇÃO DAS INDÚSTRIAS DO ESTADO DO RIO DE JANEIRO. Indíce Firjan de Gestão Fiscal. Disponível em <https://www.firjan.com.br/data/files/DE/F0/65/91/B34265107778C955F8A809C2/IFGF-2016versao-completa.pdf > Acesso em 12 maio 2019.

MASSARDI, W. O.; ABRANTES, L. A. Dependência dos municípios de Minas Gerais em relação ao FPM. Revista de Gestão, Finanças e Contabilidade, v. 1, n. 6, p. 173-187, 2016.

MENDES, M. Federalismo fiscal. In: ARVATE, P.; BIDERMAN, C. (Org.) Economia do Setor Público no Brasil. Rio de Janeiro: Editora Elsevier, 2004. p.421-461.

MONASTERIO, L. O FPM e a estranha distribuição da população dos pequenos municípios brasileiros. Texto para Discussão, Instituto de Pesquisa Econômica Aplicada (IPEA), 2013.

MORAES, D. P. D. Arrecadação tributária municipal: esforço fiscal, transferências e Lei de Responsabilidade Fiscal (Doctoral dissertation), 2006.

PEREIRA, D. B. D. S. Análise do impacto das condições de rodovias pavimentadas na renovação da frota de transporte rodoviário de carga. Publicação T. DM-00A/2006, Departamento de Engenharia Civil e Ambiental, Universidade de Brasília, 2006.

PEREIRA, L. A. G.; LESSA, S. N. O processo de planejamento e desenvolvimento do transporte rodoviário no Brasil. Caminhos de Geografia, 12(40), 2011.

PONTES, B. Os centros industriais do Estado de São Paulo. Boletim Paulista de Geografia. n. 49, p.65-142, 1974.

PORTAL DAS TRANSFERÊNCIAS CONSTITUCIONAIS SC. Informações sobre FPM (Fundo de $\begin{array}{llll}\text { Participação dos } & \text { Municípios). } & \text { Disponível } & \text { em }\end{array}$ <https://receitas.fecam.org.br/estado/FPM/informacoes> Acesso em 20 maio 2019.

PRADO, Sérgio. Transferências fiscais e financiamento municipal no Brasil. Relatório de Pesquisa Descentralização Fiscal e Cooperação Financeira Intergovernamental. EBAP/Fundação Konrad Adenauer, 2001.

REIS, J. Território e políticas do território a interpretação e a ação. Finisterra-Revista Portuguesa de Geografia, n. 100, p. 107-122, 2015.

ROMANATTO, E., et al. Caracterização econômica dos municípios goianos segundo valor adicionado dos setores de atividade. Revista Economia Ensaios, 30 (1), 2015.

SÁNCHEZ HERNÁNDEZ, J. L. El eje Irún-Aveiro: Geografía de un eje de desarrollo. Salamanca, 1998.

SANTOS, A. M. S. P. Reforma do Estado, descentralização e autonomia financeira dos municípios. Revista de Administração Mackenzie, v. 4, n. 2, 2003. 
SANTOS, K. G. B.; SANTOS, C. E. R. Dependência municipal das transferências do fundo de participação dos municípios: uma análise para os municípios do Sul da Bahia entre 2008 e 2012. IV Semana do Economista e IV Encontro de Egressos, v. 4, 2014.

SPOSITO, E. S., \& MATUSHIMA, M. K. A dinâmica econômica no Estado de São Paulo: do paradigma de área ao paradigma de eixo de desenvolvimento. Geografia econômica: temas regionais. Presidente Prudente: FCT/UNESP/PPGG, 187-216, 2002.

TRISTÃo, J. A. M. A Administração Tributária dos Municípios Brasileiros: uma avaliação do desempenho da arrecadação (Doctoral dissertation), 2003.

Esta obra está licenciada com uma Licença Creative Commons Atribuição 4.0 Internacional. 